\title{
Description of three new species of frog-biting midges (Diptera: Corethrellidae) from the Central Brazilian Amazon
}

\section{Jessica FEIJÓ ALMEIDA ${ }^{\circledR 1, *}$, Amanda MARIA PICELLI ${ }^{\circledR 2}{ }^{2}$, Adriane COSTA RAMIRES ${ }^{\circledR 3}$, Heliana Christy MATOS BELCHIOR ${ }^{\circledR 4}$, Eric Fabrício MARIALVA๑5, Hannah Inêz MONTEIRO MOREIRA LIMA ${ }^{\circledR}{ }^{6}$, Claudia María RÍOS-VELÁSQUEZ ${ }^{7}$ \& Felipe Arley COSTA PESSOA ${ }^{8}$}

\footnotetext{
1,4,5,6,7,8 Laboratório de Ecologia e Doenças Transmissíveis na Amazônia, Instituto Leônidas e Maria

Deane - Fiocruz Amazônia. Rua Terezina, nº 476, Adrianópolis, CEP: 69057-070 - Manaus, Amazonas, Brazil.

${ }^{2}$ Programa de Pós-Graduação em Zoologia. Universidade Federal do Amazonas. Avenida General Rodrigo Octavio Jordão Ramos, $n^{\circ}$ 1200, Coroado I, CEP: 69067-005 - Manaus, Amazonas, Brazil.

${ }^{3}$ Universidade Federal do Amazonas, Avenida General Rodrigo Octavio Jordão Ramos, ${ }^{\circ}{ }^{\circ} 1200$, Coroado I, CEP: 69067-005 - Manaus, Amazonas, Brazil.

1,6 Programa de Pós-Graduação em Entomologia. Instituto Nacional de Pesquisas da Amazônia. Avenida André Araújo, no 2936, Aleixo, CEP: 69060-095 - Manaus, Amazonas, Brazil. ${ }^{4}$ Programa de Pós-Graduação em Biologia da Interação Patógeno-Hospedeiro. Instituto Leônidas e Maria Deane - Fiocruz Amazônia. Rua Terezina, no 476, Adrianópolis, CEP: 69057-070 - Manaus, Amazonas, Brazil.
}
*Corresponding author: jessicalmeida1993@gmail.com
${ }^{2}$ Email: amanda.mpicelli@gmail.com
${ }^{3}$ Email: adriianeramires@gmail.com
${ }^{4}$ Email: heliana.christy@gmail.com
5Email: ericmarialva304@gmail.com
${ }^{6}$ Email: hannahinez.lima@gmail.com
${ }^{7}$ Email: claudia.rios@fiocruz.br
${ }^{8}$ Email: felipe.pessoa@fiocruz.br

\footnotetext{
${ }^{1}$ urn:Isid:zoobank.org:author:FB89280A-A7EF-4006-A1FD-02ECF170E4F6

${ }^{2}$ urn:lsid:zoobank.org:author:EFE8D11B-F507-451A-90D4-4A516B32FE9E

${ }^{3}$ urn:1sid:zoobank.org:author:99A476A6-995C-4C6B-A6D2-AB96FA62CCED

${ }^{4}$ urn:1sid:zoobank.org:author:300F446C-4166-4770-989B-0DF804314E43

${ }^{5}$ urn:lsid:zoobank.org:author:2ECCB20E-AA74-4B24-AC03-E64C3EB96E96

${ }^{6}$ urn:1sid:zoobank.org:author:C56C7CF1-9ABF-4AFB-9769-E8DD16002CF2

${ }^{7}$ urn:lsid:zoobank.org:author:C1E8D52B-73CD-4D9F-B7C1-1D62535CDCAB

${ }^{8}$ urn:1sid:zoobank.org:author:B5C2F560-E0EA-4DEB-8C9B-BBB32D65322C
}

\begin{abstract}
Three species of Corethrella Coquillett, 1902 from the state of Amazonas, Brazil are described as new to science based on female adult specimens. Corethrella cabocla Feijó, Belchior, Marialva \& Pessoa sp. nov. possesses four large setae on the frons between the ventromedial area of ommatidia, a
\end{abstract}


wide clypeus with 1-4 setae, a wing with the apex of $\mathrm{R}_{2}$ basal to the apex of $\mathrm{M}_{2}$ and with a midlength band, and with the abdomen entirely dark brown. Corethrella ielemdei Feijó, Ramires, Lima \& Pessoa sp. nov. possesses an elongated coronal suture, four large setae on the frons between the ventromedial area of ommatidia, a clypeus squarish with 42-43 setae, a wing with the apex of $R_{2}$ basal to the apex of $\mathrm{M}_{1}$ and with a midlength band and dark scales on the basal and subbasal areas of the anterior margin, legs with dark scales, and with the abdomen entirely dark brown. Corethrella menini Feijó, Picelli, Ríos-Velásquez \& Pessoa sp. nov. possesses wings with the apex of $R_{2}$ basal to the apex of $M_{2}$ and a midlength band, with darker basal scales along all veins, basal band dark scales on $\mathrm{C}, \mathrm{Sc}, \mathrm{R}, \mathrm{M}$, and $\mathrm{Cu}$ and the abdomen entirely dark brown. With the addition of the new species, the numbers of frog-biting midges described in the Amazon basin, Brazil and in Neotropical region are now 31, 49 and 80 species, respectively.

Keywords. Culicomorpha, taxonomy, hematophagous dipterans, Neotropical region.

Feijó Almeida J., Maria Picelli A., Costa Ramires A., Matos Belchior H.C., Marialva E.F., Monteiro Moreira Lima H.I., Ríos-Velásquez C.M. \& Costa Pessoa F.A. 2021. Description of three new species of frog-biting midges (Diptera: Corethrellidae) from the Central Brazilian Amazon. European Journal of Taxonomy 778: 148-166. https://doi.org/10.5852/ejt.2021.778.1577

\section{Introduction}

The monogeneric family Corethrellidae Edwards, 1932 is a widely distributed family in the tropical and subtropical areas (Borkent 2008) where species of the genus Corethrella Coquillett, 1902 locate their anuran hosts by sound instead of chemical cues (McKeever 1977; McKeever \& Hartberg 1980; Toma et al. 2005; Bartlett-Healy et al. 2008; Borkent 2008; Bernal \& de Silva 2015; Camp \& Irby 2017). Female adults are ectoparasitic, feed on host blood and are documented vectors of trypanosomatids (Johnson et al. 1993; Bernal \& Pinto 2016; Meuche et al. 2016). Recently, it was shown that members of this genus are involved in the transport of chytrid fungus, which is one of the main causes of the recent decline and extinction of amphibians (Toledo et al. 2021).

To date, the genus Corethrella includes 115 extant species and 10 extinct species. These insects have a semi cosmopolitan distribution with vast majority of extant species restricted to the tropics and subtropics (Kvifte \& Bernal 2018; Amaral et al. 2019; Baranov et al. 2019). The Neotropical region possesses the highest richness of species of Corethrella with 77 registered species (Amaral 2018; Amaral et al. 2019), of which 28 species are from the Amazon basin (Borkent 2014; Amaral et al. 2019).

There are few studies about Corethrella from the Brazilian Amazon, with 20 recorded species (Borkent 2014; Amaral et al. 2019), out of which only five have been registered for the state of Amazonas.

In an entomological survey undertaken in a degraded forest area near Manaus, the administrative capital of the state of Amazonas, several hundred frog-biting midges were collected and some new species were found. This study expands our knowledge of species of the genus Corethrella in the state of Amazonas, Brazil, by describing three new species based on female specimens.

\section{Material and methods}

Adult females were collected in a degraded forest from the experimental farm of the Universidade Federal do Amazonas (FAEXP-UFAM), located at km 38 of BR-174 highway $\left(02^{\circ} 37^{\prime} 17.1^{\prime \prime}-02^{\circ} 39^{\prime} 41.4^{\prime \prime} \mathrm{S}\right.$, and $60^{\circ} 03^{\prime} 29.1^{\prime \prime}-60^{\circ} 07^{\prime} 57.5^{\prime \prime} \mathrm{W}$ ), with an area of $3000 \mathrm{ha}$. This area is designated as secondary Amazonian upland 'terra-firme' forest (Fig. 1) and is characterized by floristic heterogeneity that includes palm trees, bromeliads, lianas, and other medium and large trees of heights between 35 to $40 \mathrm{~m}$ (Ribeiro 
1998). The forest has a fairly dense canopy and an understory with low light, characterized by the abundance of palm trees (Guillaumet \& Kahn 1982). Periodically, the extensive area of FAEXP-UFAM is flooded, due to the presence of large streams and an unregulated topography, with an altitude ranging from 42 to $130 \mathrm{~m}$ (Rojas-Ahumada et al. 2012).

Monthly air temperature variation is very low, with average temperatures between $24.6^{\circ} \mathrm{C}$ and $26.9^{\circ} \mathrm{C}$. Daily relative air humidity ranges from $75 \%$ during relatively dry days up to $92 \%$ in the rainy season, and average annual rainfall is 2,362 mm (Araújo et al. 2002).

The collections were carried out on two trails in the farm over two days, in the months of April, May, and July 2019. Frog-biting midges were collected using four HP model light traps, two with and two without light bulbs (Pugedo et al. 2005); with overnight 'frog call traps' speakers attached, as described by McKeever \& Hartberg (1980) (Fig. 2). The recorded frog sounds were from the 'sapoteca' frog library (https://ppbio.inpa.gov.br/sapoteca/paginainicial) of the Instituto Nacional de Pesquisas da Amazônia (Lima et al. 2012) (Supp. file 1).

The samples were stored in 70\% alcohol. The frog-biting midges were separated from the other families of dipterans, and morphologically identified using the identification key by Borkent (2008). Then, female samples were dissected and mounted on slides in phenol-balsam (Wirth \& Marston 1968). The diagnostic characteristics were photomicrographed using a digital system (SynopticsTM, Cambridge, UK) coupled to an optical microscope (Leica DMTM1000, Frankfurt, Germany). The Helicon Soft High Assembly program was used to obtain the final images. For species descriptions, the morphological terms proposed by Borkent (2008) were used.

The holotypes were deposited in the entomological collection of the Instituto Leônidas e Maria Deane Fiocruz Amazônia (ILMD) (Manaus, Brazil). The paratypes were housed in the entomological collections of the ILMD, Zoological collection of Instituto Nacional de Pesquisas da Amazonia (INPA) (Manaus, Brazil), Entomological collections of Instituto Oswaldo Cruz (CEIOC) (Rio de Janeiro, Brazil), and Zoological collection of Prof. Paulo Bührnheim (ZCPB) (Manaus, Brazil).
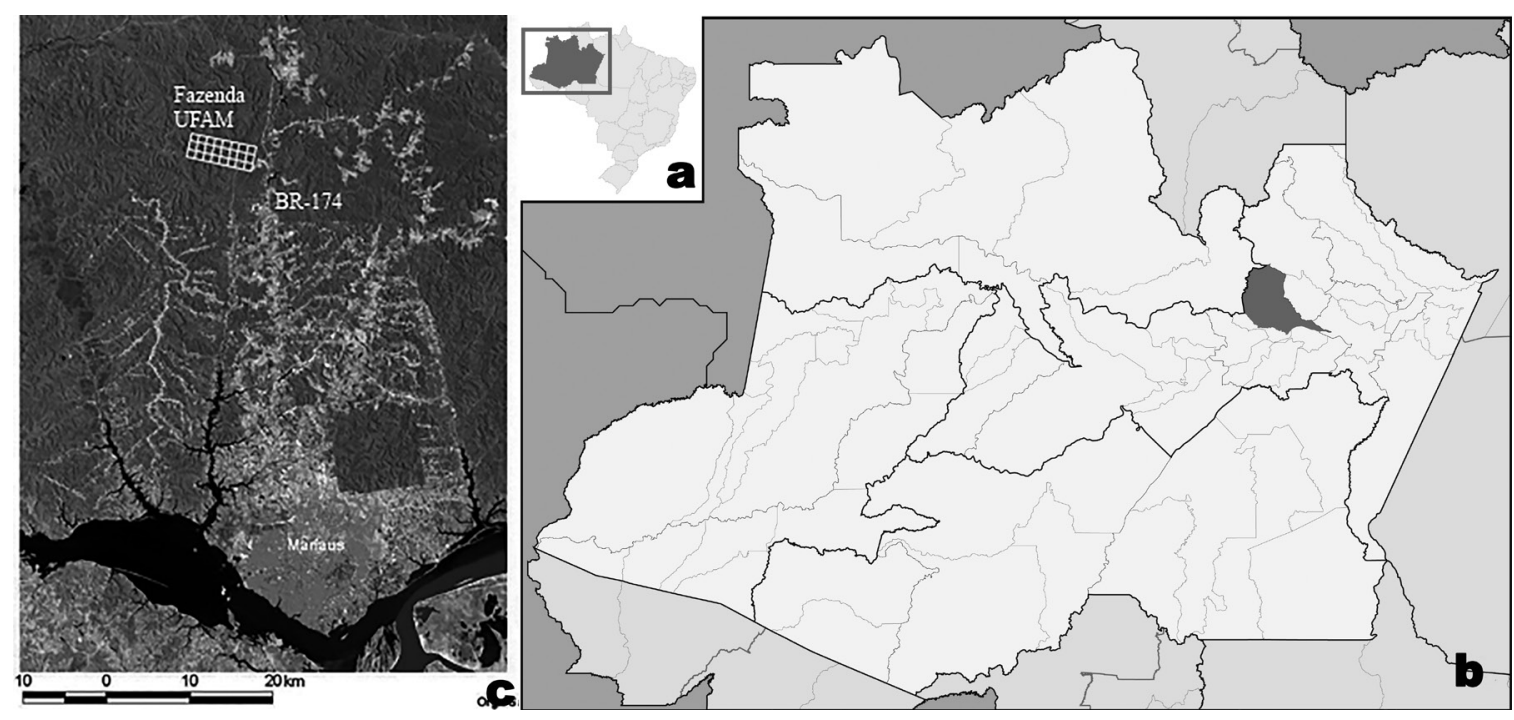

Fig. 1. Type locality of C. cabocla Feijó, Belchior, Marialva \& Pessoa sp. nov., C. ielemdei Feijó, Ramires, Lima \& Pessoa sp. nov., and C. menini Feijó, Picelli, Ríos-Velásquez \& Pessoa sp. nov. a. Map of Brazil highlighting Amazonas state. b. Municipality of Manaus. c. Experimental farm of the Universidade Federal do Amazonas with access to BR-174. 
We proposed an identification key for the new species, based on the species diagnoses in Borkent (2008), Amaral \& Pinho (2015) and Amaral et al. (2019).

\section{Results}

A total of 1270 female Corethrella were collected. In the modified light trap, 1106 individuals were captured: 395 C. cabocla sp. nov., 31 C. ielemdei sp. nov., 497 C. menini sp. nov. and 183 C. manaosensis (Lane \& Cerqueira, 1958). In the light trap, 164 frog-biting midges were collected: 25 C. cabocla sp. nov., 60 C. ielemdei sp. nov. and 79 C. manaosensis.

\section{Taxonomic descriptions}

Class Insecta Linnaeus, 1758

Order Diptera Linnaeus, 1758

Family Corethrellidae Edwards, 1932

Genus Corethrella Coquillett, 1902

Corethrella cabocla Feijó, Belchior, Marialva \& Pessoa sp. nov. urn:1sid:zoobank.org:act:A37CF95C-DF0F-452C-A9DC-D71F1DA6CE9D

Figs 3-4

\section{Diagnosis}

The species can be distinguished from other species of the genus by the following characters the female adult. Four large setae on frons between ventromedial area of ommatidia; clypeus wide, with one or four setae; antenna with flagellomere one and two darker brown while the others are light brown, flagellomere I with four sensilla coeloconica, flagellomere II with one sensillum coeloconicum, flagellomeres VIIIXIII each with a single sensillum coeloconicum; posterior portion of the dorsocentral row with a group of about six elongate setae; wing with apex of $\mathrm{R}_{2}$ basal to apex of $\mathrm{M}_{2}$ and with midlength band; abdomen entirely dark brown.

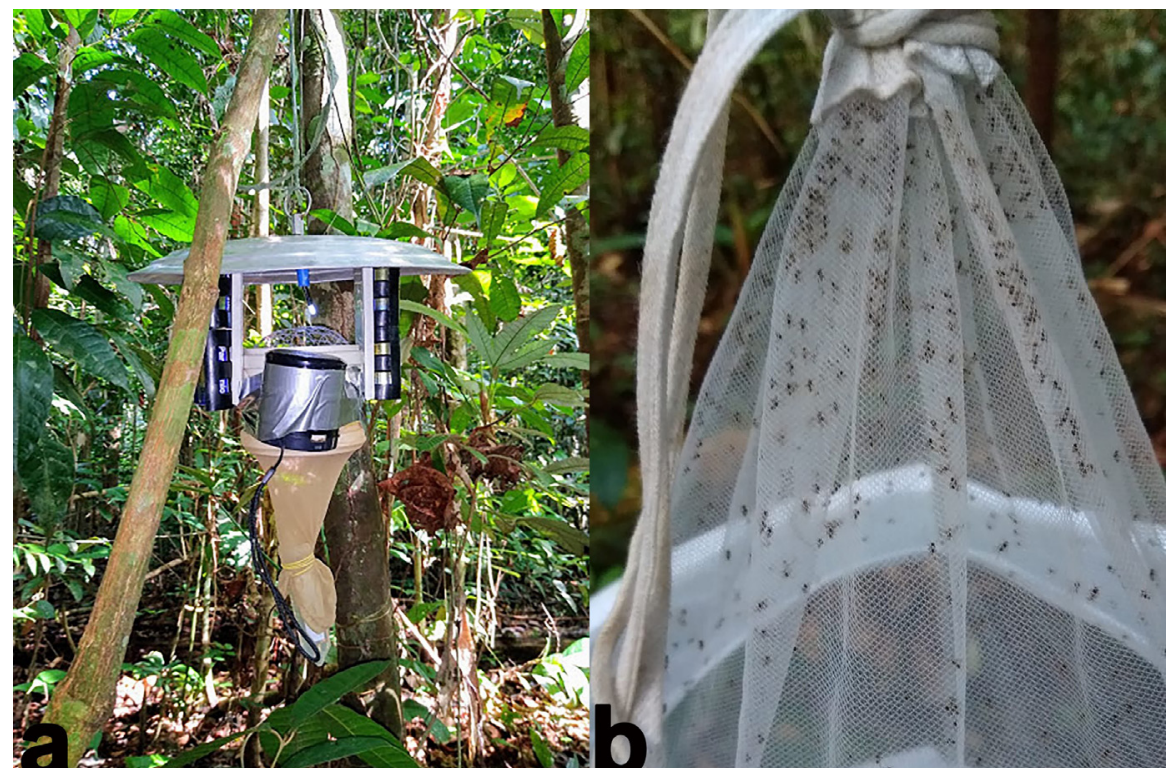

Fig. 2. Method of Corethrella collection. a. CDC light trap with a speaker attached playing looping of frog species songs from the 'sapoteca' frog library (https://ppbio.inpa.gov.br/sapoteca/paginainicial). b. Cage with dozens of Corethrella collected. 
Table 1. Distribution of sensilla coeloconica along the flagellar segments of the new species of Corethrella Coquillet, 1902. $*$ Arabic numerals $=$ number of sensilla; $* *$ Roman numerals $=$ flagellomere number.

\begin{tabular}{llll}
\hline Species & \multicolumn{4}{l}{ Distribution of sensilla coeloconica in flagellomeres } \\
\hline Corethrella cabocla sp. nov. & $4^{*}(\text { I })^{* *}$ & 1 (II) & 1 (VIII-XIII) \\
C. ielemdei sp. nov. & 2 (I) & 1 (II) & 2 (IX-XIII) \\
C. menini sp. nov. & 4 (I) & 1 (II) & 1 (IX-XIII) \\
\hline
\end{tabular}

Table 2. Wing length measurements of the new female species of Corethrella Coquillet, $1902 \mathrm{in} \mathrm{mm}$.

\begin{tabular}{llllllll}
\hline Species & Number & Wing length & Mean & $\mathbf{1 . 5 S D}$ & $\mathbf{R}_{\mathbf{1}} /$ Wing length & Mean & 1.5SD \\
\hline Corethrella cabocla sp. nov. & 10 & $1.1-1.25$ & 1.17 & 0.050 & $0.587-0.70$ & 0.663 & 0.038 \\
C. ielemdei sp. nov. & 10 & $1.45-1.62$ & 1.5 & 0.062 & $0.583-0.92$ & 0.648 & 0.130 \\
C. menini sp. nov. & 10 & $1.05-1.15$ & 1.125 & 0.038 & $0.556-0.70$ & 0.667 & 0.046
\end{tabular}

\section{Etymology}

The name 'cabocla' refers to the local name for native Amazonians, feminine gender, a mixture of Amerindian, European and African origins, resulting in a rich heritage and culture.

\section{Material examined}

\section{Holotype}

BRAZIL - $q$ adult; Amazonas State, Manaus, experimental farm of the Universidade Federal do Amazonas FAEXP-UFAM, BR-174, km 38; 02³8'44" S, 6003'13" W; 4 Apr. 2019; H. Lima and A. Ramires leg.; from tropical forest and collected with light trap; ILMD 0001-45.

\section{Paratypes}

BRAZIL • 7 q $q$; same collection data as holotype; ILMD 0001-46-50 2 9 $q$; same collection data as holotype; INPA - DIP - 004619・2 9 ; ; same collection data as holotype; CEIOC $81296 \bullet 2$ o $\circ$; same collection data as holotype; CZPB - DP - 008266, CZPB - DP - 008267.

\section{Description}

Adult female $(\mathrm{n}=10)$

Habitus. As shown in Fig. 3a.

HEAD (Fig. 3b). Laterally expanded in dorsal view. Coronal suture elongate, reaching the area between ventral margin of eye bridge (Fig. 3c). Four large setae on frons between ventromedial area of the ommatidia.

Antenna (Fig. 3b). Darker to light brown, with flagellomeres I and II darker brown, while others are light brown; flagellomere XIII apically bifurcated; sensilla coeloconica distributed according to Table 1 .

Clypeus (Fig. 3d). Wide, with one to four setae. Mandible with small pointed teeth. Palpus light brown; segment lengths: range; mean; $1.5 \mathrm{SD}$ (in $\mu \mathrm{m})$ : $1-(9.6-16.5 ; 11,5 ; 2.12), 2-(12.4-26.3 ; 18.4 ; 3.82)$, $3-(28.2-37.4 ; 36.1 ; 3.5), 4-(16.2-26.7 ; 21.7 ; 3.9), 5-(38.5-48.6 ; 43.2 ; 3.61)$; average width: range; mean; 1.5 SD (in $\mu \mathrm{m}): 3-(10.5-17.4 ; 15.7 ; 2.74), 4-(8.8-15.7 ; 12.9 ; 2.45), 5-(7.1-15.1 ; 11.5 ; 2.74)$, third palpal segment slightly expanded at midlength. 


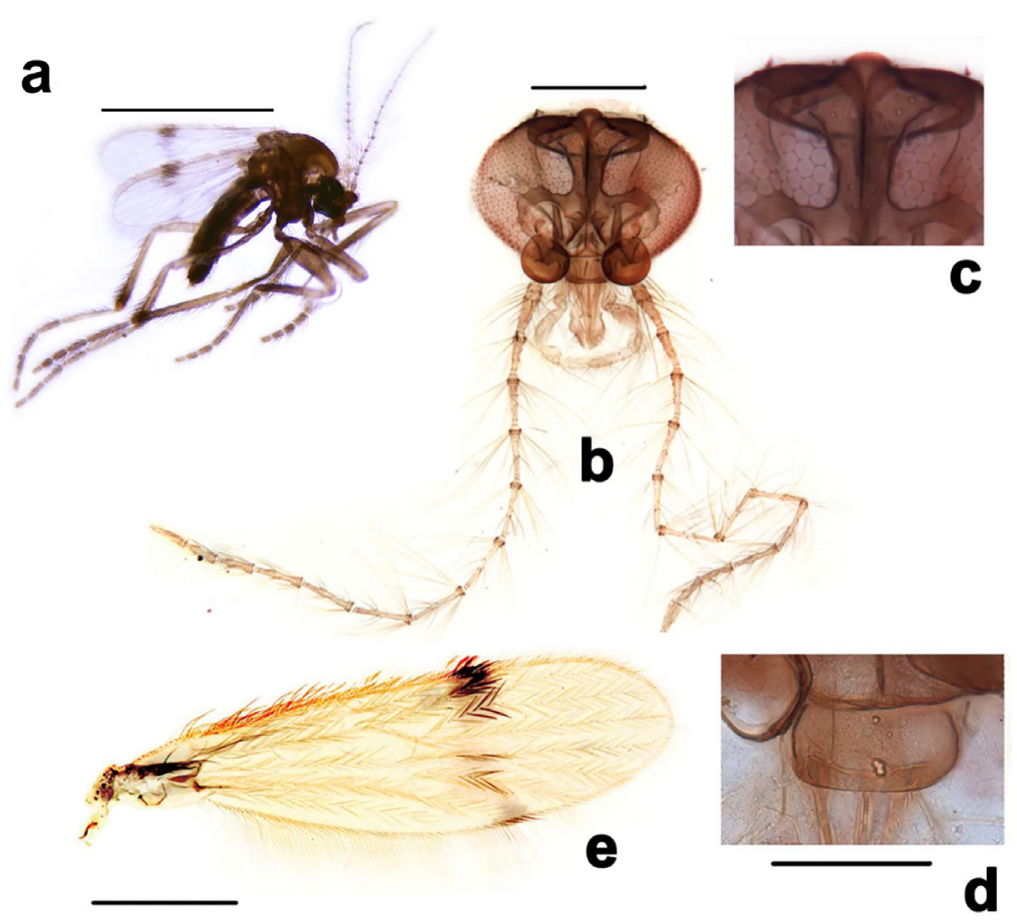

Fig. 3. Microphotography of Corethrella cabocla Feijó, Belchior, Marialva \& Pessoa sp. nov. $\uparrow$, holotype (ILMD 0001 -45). a. Habitus. b. Head. c. Head with coronal suture elongate. d. Clypeus. e. Wing. Scale bars: $\mathrm{a}=1 \mathrm{~mm} ; \mathrm{b}=100 \mu \mathrm{m} ; \mathrm{c}-\mathrm{d}=50 \mu \mathrm{m} ; \mathrm{e}=200 \mu \mathrm{m}$.

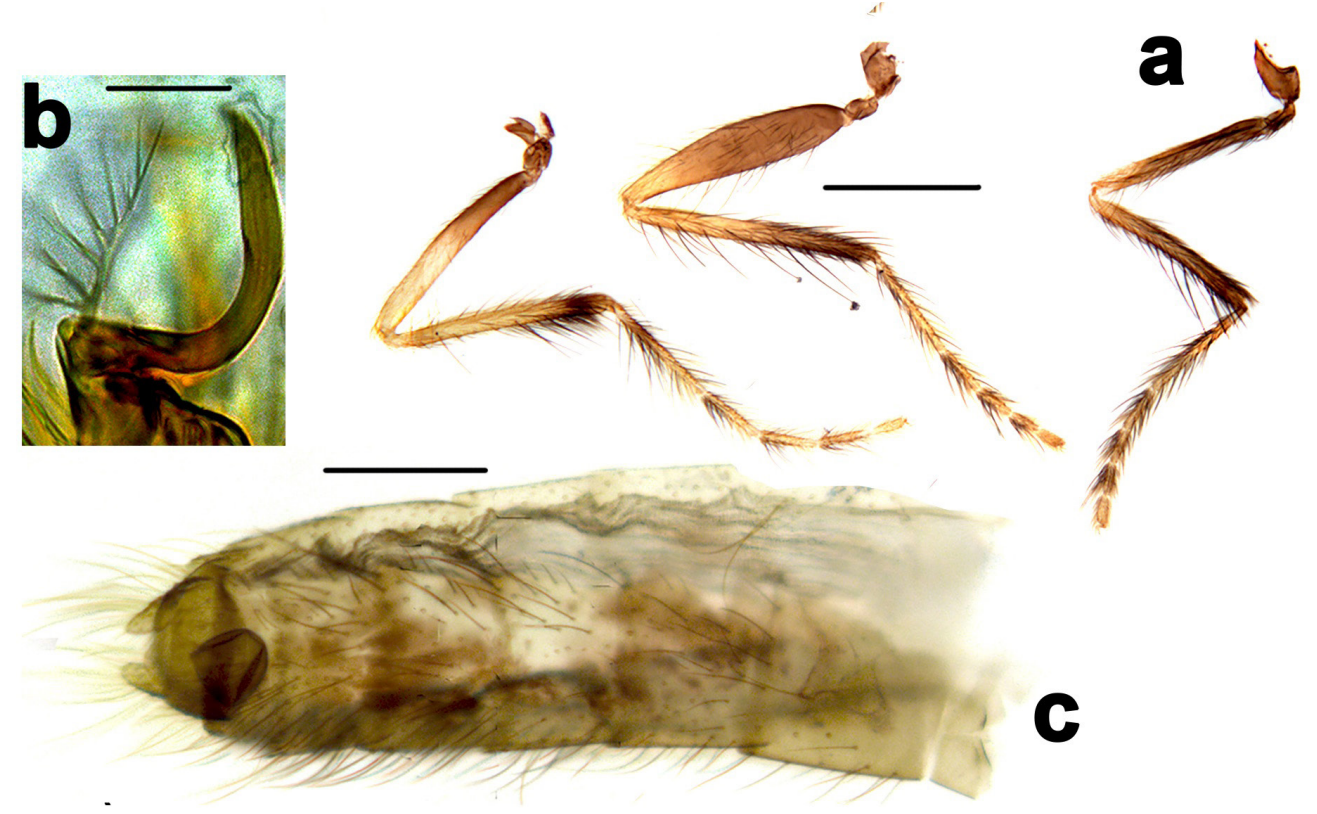

Fig. 4. Microphotography of Corethrella cabocla. Feijó, Belchior, Marialva \& Pessoa sp. nov. + , holotype (ILMD 0001-45). a. Legs. b. Tarsal claw with empodium. c. Abdomen. Scale bars: a = $100 \mu \mathrm{m} ; \mathrm{b}=10 \mu \mathrm{m} ; \mathrm{c}=100 \mu \mathrm{m}$. 
THORax. Dark brown with scutum, scutellum medium brown, pale sclerites around base of wing. Posterior portion of dorsocentral row with group of approximately six elongate setae. Prescutal suture short, not extending to dorsocentral row of setae. Anterior anepisternum medium brown, divided diagonally suture, dorsal portion about equal to ventral portion. Posterior anepisternum dark brown, divided by transversal suture, with ventral portion triangular.

WING (Fig. 3e; Table 2). Apex of $\mathrm{R}_{2}$ basal to apex of $\mathrm{M}_{2}$. Anterior margin with differently and discretely pigmented scales, with midlength band, some with darker more basal scales restricted to veins $\mathrm{C}, \mathrm{R}$ (except $\mathrm{R}_{4}$ ), and $\mathrm{M}$; veins with well-developed scales. Halter light brown, lighter than scutellum.

Legs (Fig. 4a). Dark to light brown with slender setae dark brown. Foreleg with dark brown femur to about $3 / 10$ of total light brown structure in apex region, tibia dark brown, approximately $1 / 10$ of the total light brown structure in the base region, tarsomeres 1 to 5 light brown. Midleg with dark brown femur, approximately $3 / 10$ of total light brown apically, tibia light brown from base to about $5 / 10$ of total length, other half dark brown, extending to apex, tarsomeres one to five light brown. Hindleg with dark brown femur from base to about $4 / 10$ of length, apical $\% 10$ light brown, tibia mostly light brown, about apical $2 / 10$ dark brown, tarsomeres 1 to 5 light brown. Tarsal claws equal, inserted apically; each claw without an inner tooth. Empodia (Fig. 4b) with similar thickness to apical setae of last tarsomere, longer than average diameter of last tarsomere, with five or six bifid branches.

Aвdomen. Uniformly dark brown. One ovoid spermatheca. Cercus, equally dark brown (Fig. 4c).

\section{Male}

Unknown

\section{Distribution}

This species is known only from its type locality in the experimental farm of the Universidade Federal do Amazonas FAEXP-UFAM, Manaus, Amazonas State, Brazil.

\section{Taxonomic comments}

In the Neotropical key by Borkent (2008) C. cabocla sp. nov. keys to C. lepida Borkent, 2008. However, it is distinguished from this species by having the antennal flagellomeres dark brown, whereas in C. lepida the antennal flagellomeres I-IV are light brown. Furthermore, C. cabocla sp. nov. has the first flagellomere with four sensilla coeloconica, whereas in C. lepida, the first flagellomere has been described with two sensilla, and the scutum of C. cabocla sp. nov. is dark brown and the scutellum light brown, distinct from C. lepida, in which the color of the scutum and scutellum ranges from medium to light brown. The posterior portion of the dorsocentral thorax in C. cabocla sp. nov. has a group of six elongate setae, whereas in C. lepida five elongate setae are present. The wing of $C$. cabocla sp. nov. has the apices of $\mathrm{R}_{2}$ and $\mathrm{M}_{2}$ at approximately the same level, whereas in C. lepida $\mathrm{R}_{2}$ and $\mathrm{M}_{1}$ are nearly at the same level. In C. lepida, a pale brown band has been described on each of tarsomeres 2-4 of the mid and hind leg; tarsomeres are uniformly pigmented in C. cabocla sp. nov. The abdomen of C. cabocla sp. nov. is entirely dark brown, whereas in C. lepida only segments VIII and IX are dark brown. Corethrella caribbeana Borkent, 2008 shares some characteristics with C. cabocla sp. nov. and C. lepida, but C. caribbeana is distinguished from C. cabocla sp. nov. based on several features. In C. caribbeana the flagellomeres I-III are short, whereas in C. cabocla sp. nov. they are elongate. In addition, Corethrella caribbeana has two sensilla distributed on each of flagellomeres IX-XII, whereas in C. cabocla sp. nov. there is only one on each of flagellomeres VIII-XIII. The clypeus of C. caribbeana is squarish, different from that of $C$. cabocla sp. nov., which is wide. The abdomen of $C$. caribbeana is light to dark brown, with sternites I-II slightly darker and segment IX dark brown, whereas in C. cabocla sp. nov. the abdomen is entirely dark brown. 
The holotype has a set of characteristics that do not fit within the existing species groups of Corethrella (Borkent 2008). The only apparent synapomorphy that C. cabocla sp. nov. shares with the groups fulva, appendiculata, brakeleyi and wirthi is found on the posterior dorsocentral region of the thorax, where a group of more than three elongated setae is present. The lack of knowledge of the immature stages and adult males of C. cabocla sp. nov., makes it difficult to associate the new species with a specific species group as defined by Borkent (2008).

We suggest to incorporate the following emendation to the Corethrella. Key by Borkent (2008) to identify adult females of $\boldsymbol{C}$. cabocla sp. nov.

46. Abdomen uniformly dark brown; cercus dark brown; flagellomere I with four sensilla coeloconica.

C. cabocla Feijó, Belchior, Marialva \& Pessoa sp. nov.

- Abdomen medium to dark brown, with segments VIII and IX dark brown; cercus medium brown; flagellomere I with one to two sensilla coeloconica.

47. Flagellomere I-III elongate; flagellomeres IX-XIII each with only a single sensillum coeloconicum C. lepida Borkent, 2008

- Flagellomere I-III short; female flagellomeres IX-XII each with two sensilla coeloconica.....

C. caribbeana Borkent, 2008

Corethrella ielemdei Feijó, Ramires, Lima \& Pessoa sp. nov. urn:1sid:zoobank.org:act:B2522305-03E9-4BA7-9792-696AC4A34802

Figs 5-6

\section{Diagnosis}

The species can be distinguished from other species of the genus by the following characteristics of the female adult. Coronal suture elongate, four large setae on frons between ventromedial area of ommatidia, clypeus squarish, with 42-43 setae; antenna uniformly medium brown, flagellomere I with two sensilla coeloconica, flagellomere II with one sensillum coeloconicum, flagellomeres IX-XIII with two sensilla coeloconica; posterior portion of dorsocentral row with a group of about eight elongate setae; wing with apex of $R_{2}$ basal to apex of $M_{1}$ and with midlength band and dark scales on basal and subbasal areas of anterior margin; foreleg, midleg, and hindleg with femora and foretibia with dark scales.

\section{Etymology}

The name 'ielemdei' is based on the acronym of the Instituto Leônidas e Maria Diane - Fiocruz Amazônia, an important research facility for training and providing professional experiences for biologists, including taxonomists for the Amazon region. To be treated as a noun in apposition.

\section{Material examined}

\section{Holotype}

BRAZIL - + adult; Amazonas State, Manaus, experimental farm of the Universidade Federal do Amazonas FAEXP-UFAM, BR-174 km 38; 02³8'44" S, 6003'13" W; 7 Jul. 2019; H. Lima and A. Ramires leg.; from tropical forest and collected with modified light trap ('frog call traps'); ILMD 0001-51. 


\section{Paratypes}

BRAZIL • 7 $q$; same collection data as holotype; ILMD 0001-52-56 2 + $q$; same collection data as holotype; INPA - DIP - 004618 2 우; same collection data as holotype; CEIOC $81297 \bullet 2$ 우; same collection data as holotype; CZPB - DP - 008268, CZPB - DP - 008269.

\section{Description}

$$
\text { Adult female }(\mathrm{n}=10)
$$

Habitus. As shown in Fig. 5a.

HeAD (Fig. 5b). Laterally expanded in dorsal view. Coronal suture elongate, reaching the area between ventral margin of eye bridge (Fig. 5c). Four large setae on the frons between the ventromedial area of ommatidia.

Antenna (Fig. 5b). Uniformly medium brown; flagellomere XIII apically bifurcated; sensilla coeloconica distributed according to Table 1.

Clypeus (Fig. 5d). Squarish, with 42-43 setae. Mandible with small pointed teeth. Palpus dark brown; segment lengths: range; mean; $1.5 \mathrm{SD}$ (in $\mu \mathrm{m})$ : $1-(7.6-13.8 ; 10.8 ; 2.2), 2-(15.4-22.1 ; 17.8 ; 2.6)$, $3-(31.8-38.2 ; 35.4 ; 2.4), 4-(11.4-22 ; 16.1 ; 3.1), 5-(21.8-28.7 ; 23.7 ; 2.7)$; average width: range; mean; 1.5 SD (in $\mu \mathrm{m})$ : $3-(11.1-17 ; 15.5 ; 2.3), 4-(8.1-14.5 ; 11.2 ; 2.3), 5-(6.5-11.3 ; 9.4 ; 1.6)$, third palpal segment of constant width.
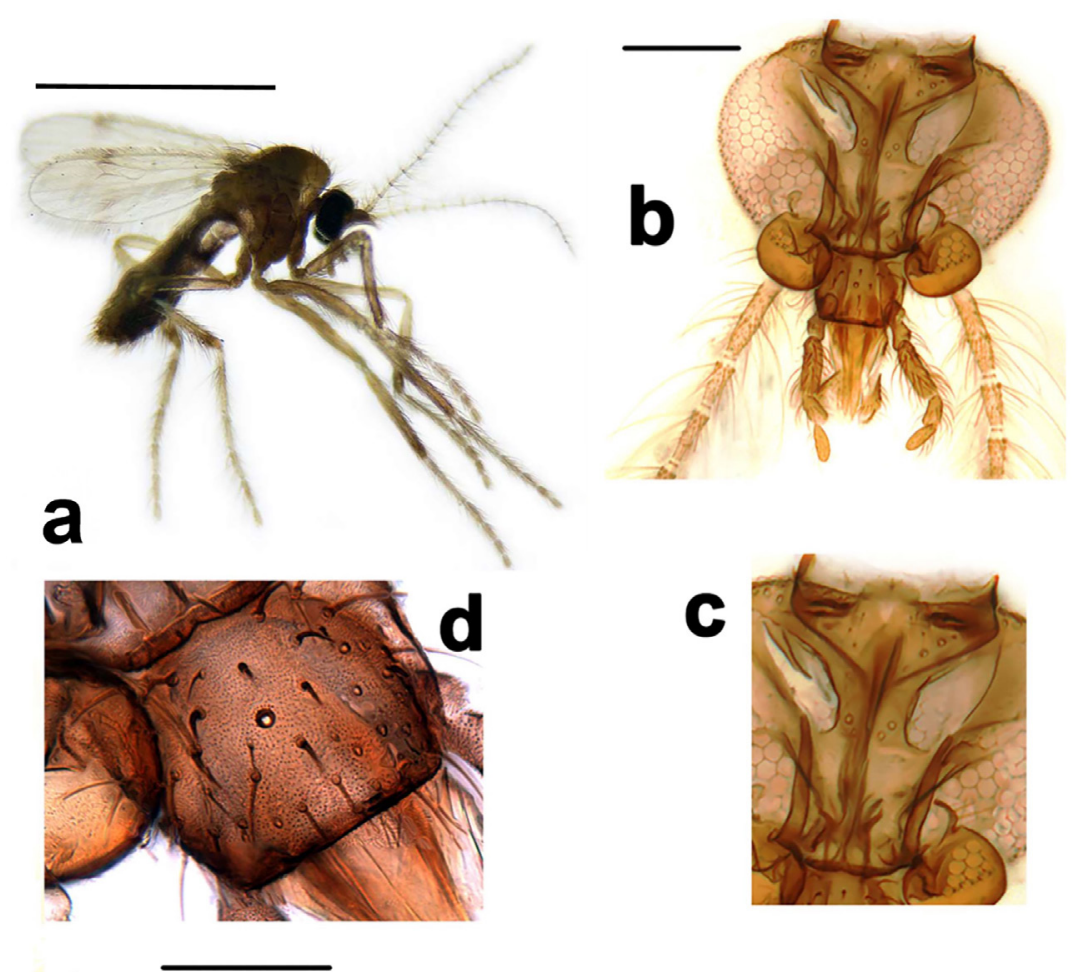

Fig. 5. Microphotography of Corethrella ielemdei. Feijó, Ramires, Lima \& Pessoa sp. nov., $q$, (ILMD $0001-51)$. a. Habitus. b. Head. c. Head with coronal suture elongate. d. Clypeus. Scale bars: a = $1 \mathrm{~mm}$; $\mathrm{b}=100 \mu \mathrm{m} ; \mathrm{c}-\mathrm{d}=50 \mu \mathrm{m}$. 
Thorax. Dark brown, scutum, scutellum, pale sclerites around the base of the wing. Posterior portion of dorsocentral row with a group of approximately eight elongate setae. Prescutal suture short, not extending to dorsocentral row of setae. Anterior anepisternum dark brown, divided by diagonal suture, dorsal portion about equal to ventral portion. Posterior anepisternum dark brown, divided by transversal suture, with ventral portion triangular.

WING (Fig. 6c; Table 2). Apex of $\mathrm{R}_{2}$ basal to apex of $\mathrm{M}_{1}$. Anterior margin with differently and discretely pigmented scales, with midlength band, with darker more basal scales along all veins (except $A_{1}$ ); some scattered dark scales on basal and subbasal areas of anterior margin; veins with well-developed scales. Halter dark brown, darker than scutellum.

Legs (Fig. 6a). Dark to light brown and slender setae light brown. Foreleg with femur entirely dark brown and thin dark scales on upper margin of medial portion extending near apex of femur; tibia dark brown, with thin dark scales on lower margin extending from the base to middle of the structure, first tarsomere dark brown and about $2 / 10$ of the total light brown structure in base region, and other tarsomeres dark brown. Midleg with dark brown femur with a tuft of thin dark scales near apex region of the structure, tibia, and tarsomeres entirely dark brown. Hindleg with entirely light brown femur with a tuft of dark scales on posterior margin near apex of the structure, tibia predominantly light brown but about $3 / 10$ dark brown in the apex region, tarsomeres 1 to 5 dark brown; tarsal claws equal, inserted apically; each claw without inner tooth. Empodia (Fig. 6b). With thickness larger than apical bristles of last tarsomere, longer than average diameter of last tarsomere, with seven bifid branches.

AвDomen (Fig. 6d). Uniformly dark brown. One ovoid spermatheca. Cercus dark brown.

\section{Male}

Unknown
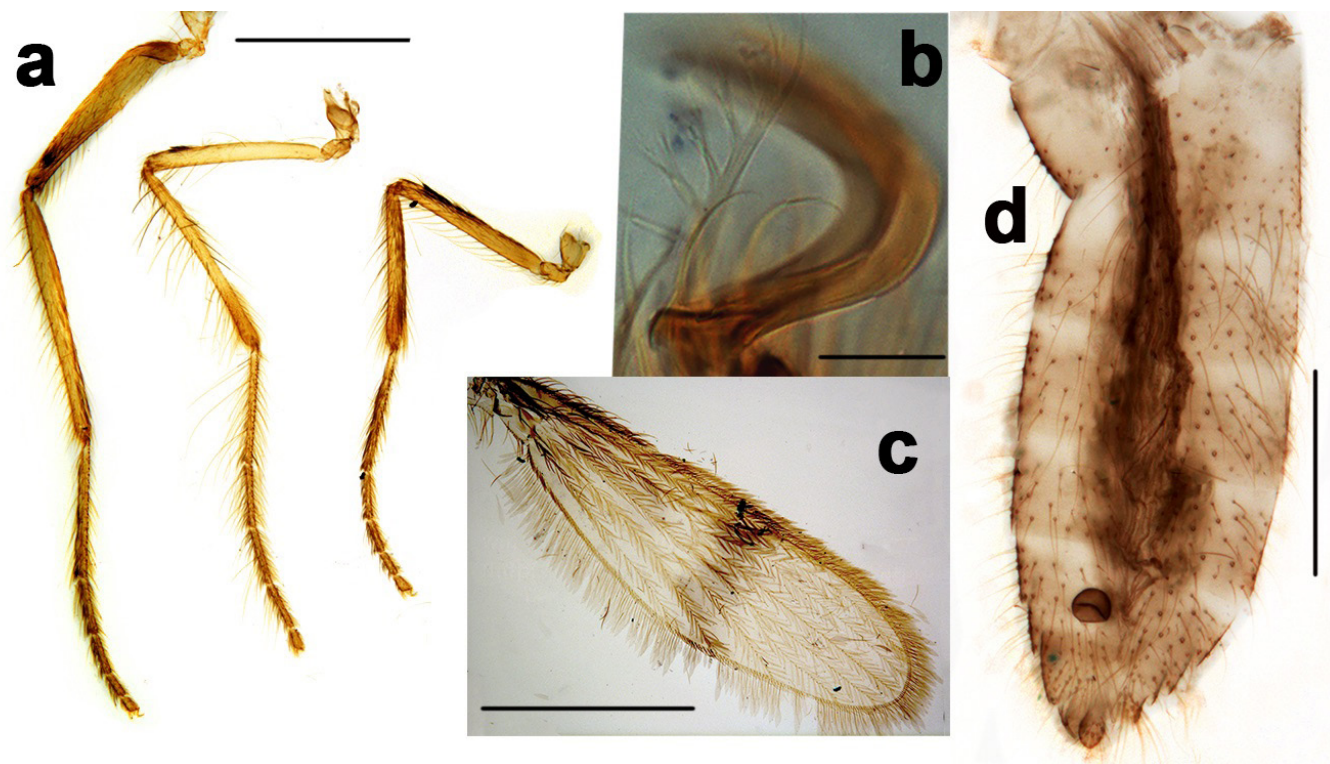

Fig. 6. Microphotography of Corethrella ielemdei Feijó, Ramires, Lima \& Pessoa sp. nov. + , (ILMD 000 - 51). a. Legs. b. Tarsal claw with empodium. c. Wings. d. Abdomen. Scale bars: $a=100 \mu \mathrm{m} ; \mathrm{b}=$ $10 \mu \mathrm{m} ; \mathrm{c}-\mathrm{d}=500 \mu \mathrm{m}$. 


\section{Distribution}

The species is known only from its type locality in the experimental farm of the Universidade Federal do Amazonas FAEXP-UFAM, Manaus, Amazonas State, Brazil.

\section{Taxonomic comments}

The characters present in C. ielemdei sp. nov., as distribution of sensilla coeloconica, eight setae in the dorsocentral region of the thorax, and dark brown cercus and halter, are shared with C. squamifemora Borkent, 2008 and C. hirta Borkent, 2008. However, they can be distinguished from these species by the presence of an elongated coronal suture (in C. squamifemora and in C. hirta, they are shorter), four long setae between the ommatidia (in C. squamifemora and in C. hirta, there are just two), and squarish clypeus (in C. squamifemora and in C. hirta, they are broadly roundish). The presence of an elongate coronal suture, a dark antenna, and the wing with the apex of $\mathrm{R}_{2}$ basal to apex of $\mathrm{M}_{1}$ in $C$. ielemdei sp. nov. are also shared with C. albicoxa Borkent, 2008, C. appendiculata Grabham, 1906, C. calathicola Edwards, 1930, and C. melanica Lane \& Aitken, 1956. However, the new species can be distinguished from these by the dark brown palpus in comparison to the pale palpus in C. albicoxa, $C$. appendiculata, C. calathicola, and C. melanica. The third palpal segment is evenly broad throughout its length in C. ielemdei sp. nov., whereas in C. albicoxa, C. appendiculata, C. calathicola, and C. melanica it is somewhat swollen in the middle of this segment. In addition, the pattern and distribution of dark bands and scales along the wing are different in C. ielemdei sp. nov., C. albicoxa, C. appendiculata, C. calathicola, and C. melanica.

Corethrella ielemdei sp. nov. shares characteristics with species in the appendiculata group (Borkent 2008), including scales on the femora and tibiae, and having a group of more than three elongated setae in posterior dorsocentral region of the thorax. The color of the medial and posterior femur distinguishes C. ielemdei sp. nov. from the other species of this group. The description of males and immature stages will probably confirm the inclusion of this species in the appendiculata group.

We suggest to incorporate the following couplets in the Corethrella. Key by (Borkent 2008) to identify adult females of $C$. ielemdei sp. nov.

47. Midfemur dark brown, contrasting with hindfemur which is entirely light brown

C. ielemdei sp. nov.

- Base of the midfemur with distinct color; base of the hindfemur ranging from light brown to dark brown 48

Corethrella menini Feijó, Picelli, Ríos-Velásquez \& Pessoa sp. nov. urn:1sid:zoobank.org:act:D2973CA5-CC66-4EFA-A223-8697D048D1AE

Figs $7-8$

\section{Diagnosis}

The species can be distinguished from other species of the genus by the following characteristics of the female adult. Coronal suture elongate, two large setae on the frons between ventromedial area of ommatidia, clypeus squarish, with three setae; antenna dark brown, flagellomere I with four sensilla coeloconica, flagellomere II with one sensillum coeloconicum, flagellomeres IX-XIII with one sensillum coeloconicum; posterior portion of dorsocentral row with a group of about six elongate setae; wing with apex of $R_{2}$ basal to apex of $M_{2}$ and midlength band, with darker more basal scales along all on veins, basal band dark scales on $\mathrm{C}, \mathrm{Sc}, \mathrm{R}, \mathrm{M}$, and $\mathrm{Cu}$; abdomen, completely dark brown. 


\section{Etymology}

Corethrella menini sp. nov. is named in honor of Dr. Marcelo Menin as a tribute to his important work as a herpetologist, focused on ecology and biology of anurans. Marcelo was a professor of zoology who inspired dozens of zoology students, a beloved friend. He passed away too young during the COVID pandemic.

\section{Material examined}

\section{Holotype}

BRAZIL - + adult; Amazonas State, Manaus, experimental farm of the Universidade Federal do Amazonas FAEXP-UFAM, BR-174, km 38; 02 $38^{\prime} 38^{\prime} \mathrm{S}, 60^{\circ} 03^{\prime} 13^{\prime} \mathrm{W} ; 14 \mathrm{Jul}$. 2019; H. Lima and A. Ramires leg.; from tropical forest and collected with modified light trap ('frog call traps') ILMD 000157.

\section{Paratypes}

BRAZIL • 7q $q$; same collection data as holotype; ILMD 0001-58-62 • 2 q+ ; same collection data as holotype; INPA - DIP - 004617 • 2 ㅇ; ; same collection data as holotype; CEIOC $81298 \bullet 2$ q $q$; same collection data as holotype; CZPB - DP - 008264, CZPB - DP - 008265.

\section{Description}

Adult female $(\mathrm{n}=10)$

Habitus. As shown in Fig. 7a.

HEAD (Fig. 7b). Laterally expanded in dorsal view. Coronal suture elongate, reaching the area between ventral margin of eye bridge (Fig. 7c). Two large setae on frons between ventromedial area of ommatidia.

AntenNAE. Dark brown, with flagellomere XIII without apical bifurcation; sensilla coeloconica distributed according to Table 1.

Clypeus (Fig. 7d). Squarish with three setae. Mandible with small pointed teeth. Palpus dark brown; segment lengths: range; mean; $1.5 \mathrm{SD}$ (in $\mu \mathrm{m}): 1-(5.3-10.9 ; 8.7 ; 1.9), 2-(9.9-16.8 ; 13.2 ; 2.7), 3-(29.7-$ $43.3 ; 34.5 ; 4.7), 4-(11.7-23.7 ; 19.5 ; 3.8), 5-(27.3-44.7 ; 41 ; 5.9)$; average width: range; mean; $1.5 \mathrm{SD}$ (in $\mu \mathrm{m})$ : $3-(10.6-15.9 ; 12.11 ; 1.9), 4-(9.4-15.6 ; 10.65 ; 2.4), 5-(6.8-15.8 ; 11.3 ; 3.1)$, and the third palpal segment was nearly constant and swollen at or near midlength.

Thorax (Fig. 8a). Dark brown, scutum, scutellum, pale sclerites around base of wing. Posterior portion of dorsocentral row with a group of six elongate setae. Prescutal suture short, not extending to dorsocentral row of setae. Anterior anepisternum dark brown, divided by diagonal suture, dorsal portion about equal to ventral portion. Posterior anepisternum dark brown, divided by transversal suture, with ventral portion triangular.

WING (Fig. 7e) (Table 2). Apex of $\mathrm{R}_{2}$ basal to apex of $\mathrm{M}_{2}$. Anterior margin with differently and discretely pigmented scales, midlength band, with darker more basal scales along all veins, basal dark scales on $\mathrm{C}$, $\mathrm{Sc}, \mathrm{R}, \mathrm{M}$, and $\mathrm{Cu}$; veins with well-developed scales. Halter dark brown, equal to the scutellum.

LEGS (Fig. 8a). Dark brown and slender setae dark brown. Foreleg with femur, tibia, and tarsomeres entirely dark brown. Midleg with femur, tibia, and tarsomeres entirely dark brown. Hindleg with femurs dark brown to about $3 / 10$ of the total light brown structure in apex region, tibia dark brown but apical and basal extremities light brown, tarsomeres 1 to 5 light brown. Tarsal claws equal, inserted apically; each claw without an inner tooth. Empodia (Fig. 8b) with a thickness equal to apical bristles of last tarsomere, smaller than average diameter of last tarsomere, with one bifid branch. 
Aвdomen (Fig. 8c). Uniformly dark brown. One ovoid spermatheca. Cercus equally dark brown.

\section{Male \\ Unknown}

\section{Distribution}

This species is known only from its type locality in the experimental farm of the Universidade Federal do Amazonas FAEXP-UFAM, Manaus, Amazonas State, Brazil.

\section{Taxonomic comments}

The structures present in C. menini sp. nov., such as the elongated coronal suture, the presence of two long frontal bristles between ommatidia, the third palpal segment being almost constant in width, and the group of six bristles in the thoracic dorsocentral region are characteristic for species in the brakeleyi group: C. hispaniolensis Borkent, 2008, C. puella Shannon \& Del Ponte, 1928, C. condita Borkent, 2008, C. brakeleyi (Coquillett, 1902), and C. longituba Belkin, Heinemann \& Page, 1970. However, C. menini sp. nov. can be distinguished from these based on the color of the palpus (dark brown in C. menini sp. nov., pale in C. hispaniolensis and C. longituba, and medium brown in C. puella, C. condita, and C. brakeleyi), the number of sensilla coeloconica on the flagellomeres, the band pattern and scales along the wing, and the color of the halter (dark brown in C. menini sp. nov. and pale in C. hispaniolensis, C. puella, C. condita, C. brakeleyi, and C. longituba). The squarish clypeus and the dark brown color of the antenna, halter, and cercus are characteristics shared by $C$. menini sp. nov., C. curta Borkent, 2008, and C. ranapungens Borkent, 2008. However, the thoracic dorsocentral region of $C$. curta and C. ranapungens have a group of three and four elongated bristles, respectively as opposed to six setae in C. menini sp. nov.; in addition, C. menini sp. nov. has the apex of $\mathrm{R}_{2}$ basal to the apex of $\mathrm{M}_{2}$, whereas in C. curta and C. ranapungens, the apex of $\mathrm{R}_{2}$ is basal to the apex of $\mathrm{M}_{1}$. Other characters, such as the color pattern of the thorax and palpus, can also be used to distinguish the species C. menini sp. nov. from $C$. curta and C. ranapungens. The new species likely belongs to the brakeleyi group, which includes eight species. However, male characters are still necessary to support this hypothesis because the occurrence of wings with apical bands, a characteristic that defines the group, is more commonly found in adult males.

\section{We suggest to add the following couplets to the Corethrella key by Borkent (2008) to identify adult females of $C$. menini sp. nov.}

90. Flagellomeres IX-XII each with two sensilla coeloconica. C. incompta Borkent, 2008

- Flagellomeres IX-XII each with a single sensillum coeloconicum . 91

91. Flagellomere I with one or two sensilla coeloconica; dorsocentral region of the thorax with a group of 4 elongate setae; wing with apex of $\mathrm{R}_{2}$ basal to apex of $\mathrm{M}_{1}$ C. ranapungens Borkent, 2008

- Flagellomere I with four sensilla coeloconica; dorsocentral region of the thorax with a group of 6 elongate setae; wing with apex of $\mathrm{R}_{2}$ basal to apex of $\mathrm{M}_{2}$ 


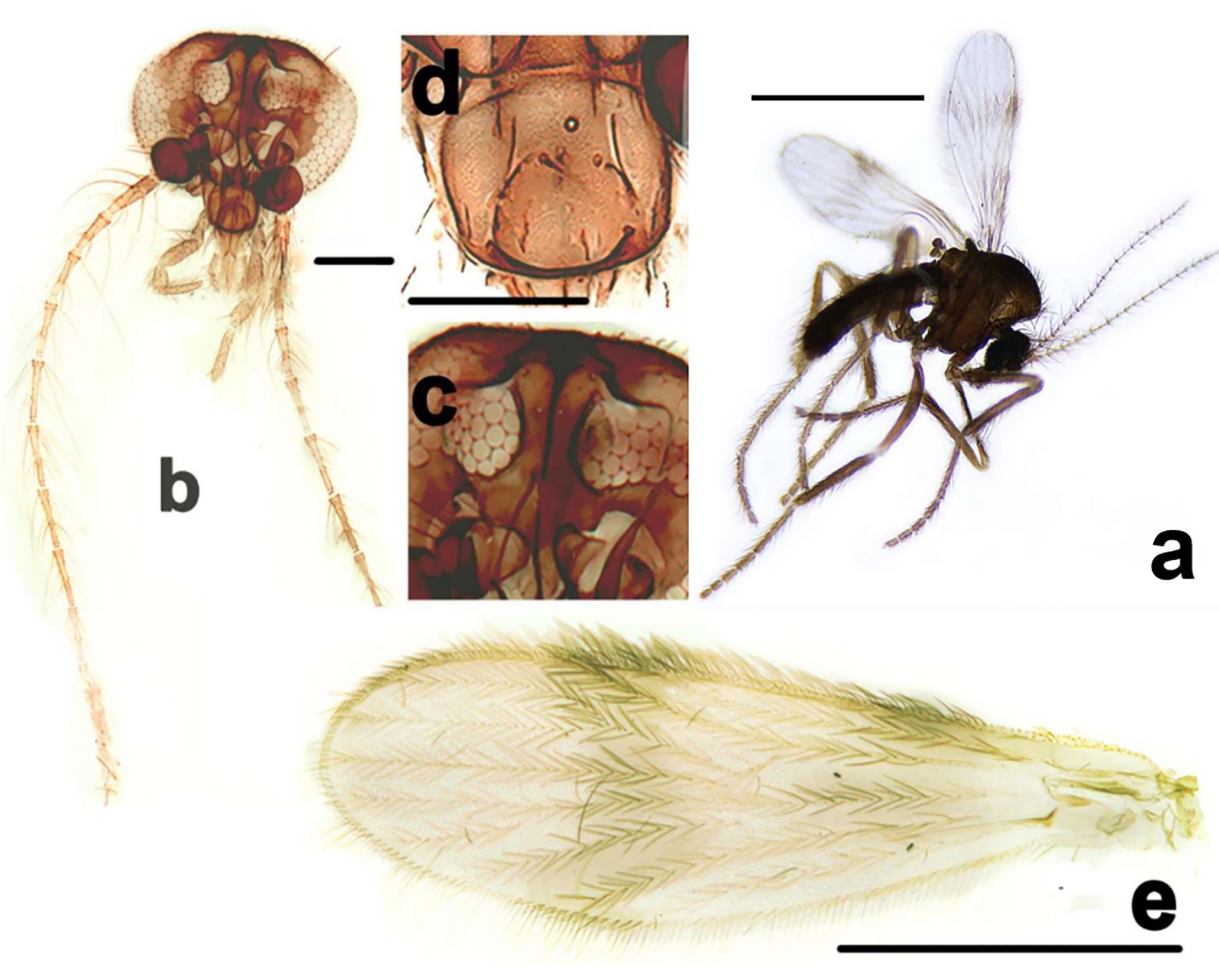

Fig. 7. Microphotography of Corethrella menini Feijó, Picelli, Ríos-Velásquez \& Pessoa sp. nov. + , holotype (ILMD 0001 - 57). a. Habitus. b. Head. c. Head with coronal suture elongate. d. Clypeus. e.Wing. Scale bars: $a=1 \mathrm{~mm} ; b=100 \mu \mathrm{m} ; \mathrm{c}-\mathrm{d}=50 \mu \mathrm{m} ; \mathrm{e}=500 \mu \mathrm{m}$.

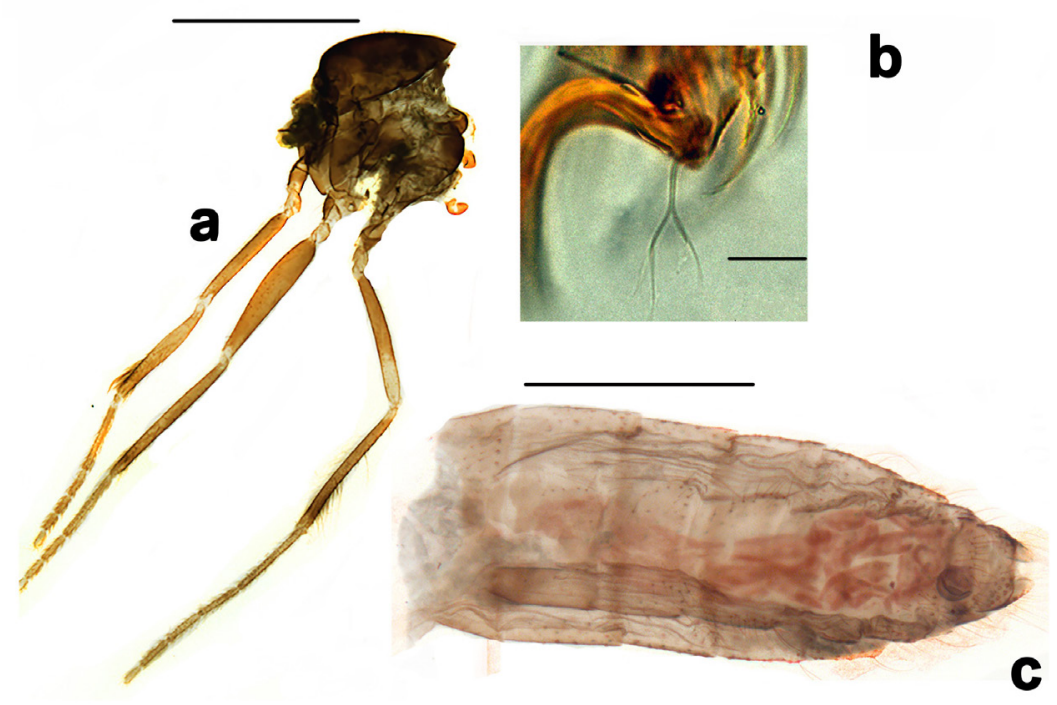

Fig. 8. Microphotography of Corethrella menini Feijó, Picelli, Ríos-Velásquez \& Pessoa sp. nov. $q$, holotype (ILMD 0001 - 57). a. Thorax and legs. b. Tarsal claw with empodia. c. Abdomen. Scale bars: $\mathrm{a}-\mathrm{c}=500 \mu \mathrm{m} ; \mathrm{b}=10 \mu \mathrm{m}$. 
Identification key to female Amazon basin species of Corethrella.

The species C. maculata Lane, 1939, C. shannoni Lane, 1939 and C. munteantaroku Amaral, Mariano $\&$ Pinho, 2019 are not included as females of these species have not been described yet.

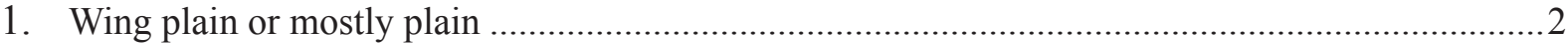

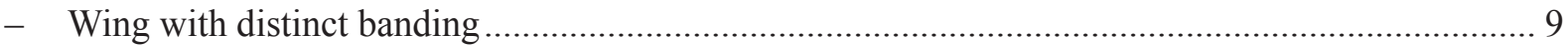

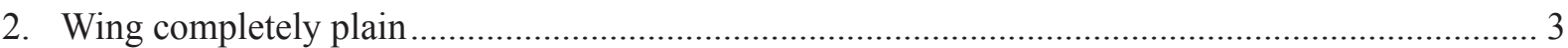

- Mostly plain, with very light poorly defined midlength band, anterior margin of wing uniformly pigmented

C. blanda Dyar, 1928

3. Tergites II-VIII with most of the posterior portion with dark band, tergites I, IX probably uniformly light brown

C. alticola Lane, 1989

- Abdominal tergites uniformly pigmented

4. Palpus pale; clypeus with 1 seta

C. unisetosa Borkent, 2008

- Palpus darker, clypeus with one or more than one seta 5

5. Thorax light brown. Scutum light brown with lateral vitta distinctly dark brown

C. manaosensis (Lane \& Cerqueira, 1958)

- Thorax medium to dark brown

6. Thorax almost uniformly medium to dark brown but with the scutellum lighter laterally and with a

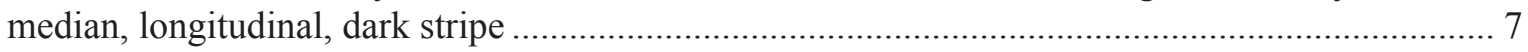

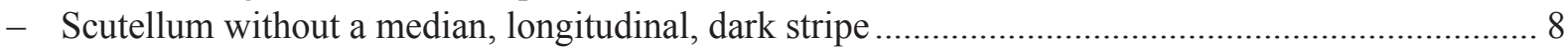

7. Antennal flagellomere I-II pale, abdomen light brown, with sternite II darker

C. tarsata Lane, 1942

- Antenna uniformly brown, abdomen with segments medium brown ....... C. redacta Borkent, 2008

8. Thorax uniformly dark brown contrasting with a pale halter, the midfemur with darker pigmentation at its base, and hind leg femur and tibia uniformly pigmented

C. peruviana Lane, 1939

- Thorax uniformly medium brown, the halter as dark as the scutellum, with flagellomeres I-III elongate, foretrochanter pale and contrasting with dark forefemur.

C. amazonica Lane, 1939

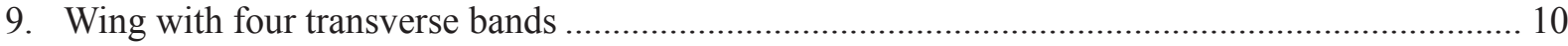

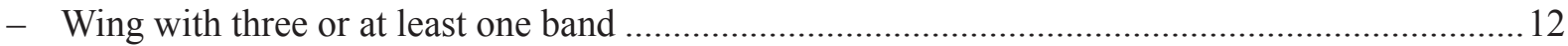

10. Halter dark brown (similar to the scutellum) .............. C. quadrivittata Shannon \& Del Ponte, 1928

- Halter pale or light brown (lighter than the scutellum) .............................................................. 11

11. Abdomen and cercus medium brown

C. vittata Lane, 1939

- Abdomen dark brown with, in some, segments VIII, IX slightly darker, cercus dark brown

C. edwardsi Lane, 1942

12. Wing with basal and midlength band of dark scales. C. menini sp. nov.

- Wing without basal band but with a discreet or well-developed midlength and dark scales ..........13

13. Two large setae on frons between ventromedial area of ommatidia .............................................. 14

- Up to four large setae on frons between ventromedial area of ommatidia .....................................24 
14. Flagellomeres I and II short with flagellomere I nearly globular, flagellomere III elongate

C. bicolor Borkent, 2008

- Flagellomeres I-III otherwise

15. Thorax dark brown, halter and scutellum equally dark brown ................................................... 16

- Thorax dark brown, halter pale, much lighter than scutellum ...................................................... 18

16. Midfemur and hind tibia uniformly dark brown

C. travassosi Lane, 1942

- Midfemur dark brown, base of hind tibia pale, similar to the apex of hind femur

17. Flagellomeres IX-XIII each with one sensillum coeloconicum

C. ranapungens Borkent, 2008

- Flagellomeres IX-XII each with two sensilla coeloconica

C. incompta Borkent, 2008

18. Primarily medium to dark brown palpus

- Primarily pale or light brown palpus

19. Clypeus wide, few setae (less than 5)

C. fuscipalpis Borkent, 2008

- Clypeus elongate, more than 5 to 10 setae C. puella Shannon \& Del Ponte, 1928

20. Flagellomere III without a sensillum coeloconicum.

- Flagellomere III with a sensillum coeloconicum.

21. Presence of 2 sensilla coeloconica on flagellomeres X-XII.

C. ananacola Dyar, 1926

- Absence of 2 sensilla coeloconica on flagellomeres X-XII .

22. Coronal suture short

C. dicosimoae Borkent, 2008

- Coronal suture elongate. C. melanica Lane \& Aitken, 1956

23. Coronal suture elongate, extending ventrally past ommatidia.

C. inca Lane, 1939

- Coronal suture short, extending ventrally about midway along the area between ommatidia

C. selvicola Lane, 1939

24. Clypeus squarish, with more than 10 setae.

C. ielemdei sp. nov.

- Clypeus wide, with up to four setae.

25. Thorax with a group of eight setae.

C. appendiculata Grabham, 1906

- Thorax with a group of five to six setae

26. Legs without any well-defined pigmentation pattern (hind tibia slightly darker apically and hind femur slightly less pigmented distally

C. yanomami Amaral, Mariano \& Pinho, 2019

- Legs with any well-defined pigmentation pattern

27. Antenna with flagellomere I and II dark brown and the others light brown; flagellomere I with four sensilla; scutum and scutellum medium brown; abdomen entirely dark brown....C. cabocla sp. nov.

- Antenna with flagellomere I-IV light brown and V-XIII progressively dark; flagellomere I with 2 sensilla; scutum and scutellum light to medium brown; abdomen light brown to medium with segments VIII and IX darker

C. lepida Borkent, 2008 


\section{Discussion}

The possible preference for the calls of certain frog species seems to be a relevant factor that influences the diversity of frog-biting midges captured (Ambrozio-Assis et al. 2019). In our study, it was not possible to evaluate the preference of species of Corethrella to a specific type of frog call, because we used a database with more than 80 frog sounds. Most of the individuals were collected in the modified trap, with speakers; similar results were also found in studies of Caldart et al. (2016). Some other studies carried out in Brazil (Amaral \& Pinho 2015; Amaral et al. 2019; Caldart et al. 2016), using same collection methods, captured less samples. Partly, this can be explained by the differences in collection methods, frog and toad mosquito fauna, and biomes.

Of the four species of frog-biting midges collected at FAEXP-UFAM, three are new to science. Collections of Corethrella are being carried out in several regions of the Brazilian Amazon and soon we hope to obtain data in order to expand the distribution of frog-biting midges, especially in areas with no existing records, but with favorable conditions for their establishment. The uncertainty of associating the new species to the groups described by Borkent (2008), exemplified the need to collect immature stages and males to robustly evaluate the phylogenetic position of Corethrellidae species.

The Amazon Basin is a vast heterogeneous area that constitutes half of the Brazilian territory, but very few surveys have been conducted for Corethrella in this region. Extensive ecological and biodiversity studies, especially focussing on areas with geographical barriers, e.g., areas between large rivers, are necessary to understand the overall distribution and abundance of these species in Brazil.

\section{Acknowledgments}

We are grateful to the Conselho Nacional de Desenvolvimento Científico e Tecnológico (CNPq) for the productivity fellowship to Pessoa, and to Vice Presidencia de Educação, Informação e Comunicação (VPEIC-Fiocruz) for a scholarship. We thank Fundação de Amparo à Pesquisa do Estado do Amazonas/FAPEAM for financial support (Programa de Excelência em Pesquisa Básica e Aplicada em Saúde, call 004/2014 - PROEP, and Universal Amazonas, call 006/2019) and Fundação para o Desenvolvimento Científico e Tecnológico em Saúde (FIOTEC) for supporting this research. We also thank Editage (www.editage.com) for English language editing. Sampling was conducted under license number 12186, issued by SISBIO-ICMBio. The authors declare no conflicts of interest.

\section{References}

Amaral A.P. do 2018. Taxonomia de Corethrellidae (Diptera) do Brasil. PhD thesis.Universidade Federal de Santa Catarina.

Amaral A.P. \& Pinho L.C. 2015. New species and records of frog-biting midges from southern Brazil (Diptera: Corethrellidae). Zootaxa 3946 (2): 274-284. https://doi.org/10.11646/zootaxa.3946.2.9

Amaral A.P., Mariano R. \& Pinho L.C. 2019. Four new species and some new records of Brazilian frog-biting midges (Diptera: Corethrellidae). Zootaxa 4706 (1): 103-120.

https://doi.org/10.11646/zootaxa.4706.1.4

Ambrozio-Assis A., Lopes B.C., Amaral A.P., Pinho L.C., Peeters E.T.H.M. \& Neckel-Oliveira S. 2019. Preferences for anuran calls in hematophagous corethrellids (Diptera: Corethrellidae) from Southern Brazil. Austral Entomology 58 (3): 622-628. https://doi.org/10.1111/aen.12376

Araújo A.C., Nobre A.D., Kruijt B., Elbers J.A., Dallarosa R., Stefani P., Randow C. von., Manzi A.O., Culf A.D., Gash J.H.C., Valentini R. \& Kabat P. 2002. Comparative measurements of carbon dioxide fluxes from two nearby towers in a central Amazonian rainforest: The Manaus LBA site. Journal of 
FEIJÓ ALMEIDA J. et al., Three new species of Corethrellidae from Brazilian Amazon

Geophysical Research: Atmospheres 107 (D20): LBA 58-1-LBA 58-20.

https://doi.org/10.1029/2001JD000676

Baranov V., Kvifte G.M., Müller P. \& Bernal X.E. 2019. A new species of fossil Corethrella (Diptera, Corethrellidae) from mid-Cretaceous Burmese amber. Cretaceous Research 101: 84-91.

https://doi.org/10.1016/j.cretres.2019.05.002

Bartlett-Healy K., Crans W. \& Gaugler R. 2008. Phonotaxis to Amphibian Vocalizations in Culex territans (Diptera: Culicidae). Annals of the Entomological Society of America 101 (1): 95-103.

https://doi.org/dnj9mk

Bernal X.E. \& Pinto C.M. 2016. Sexual differences in prevalence of a new species of trypanosome infecting túngara frogs. International Journal for Parasitology: Parasites and Wildlife 5 (1): 40-47. https://doi.org/10.1016/j.ijppaw.2016.01.005

Bernal X.E. \& de Silva P. 2015. Cues used in host-seeking behavior by frog-biting midges (Corethrella spp. Coquillet). Journal of Vector Ecology 40 (1): 122-128. https://doi.org/10.1111/jvec.12140

Borkent A. 2008. The frog-biting midges of the world (Corethrellidae: Diptera). Zootaxa 1804 (1): 1-456. https://doi.org/10.11646/zootaxa.1804.1.1

Borkent A. 2014. World catalog of extant and fossil Corethrellidae (Diptera). Zootaxa. 3796 (3): 453468. https://doi.org/10.11646/zootaxa.3796.3.3

Caldart V.M., Santos M.B. dos, Iop S., Pinho L.C. \& Cechin S.Z. 2016. Hematophagous flies attracted to frog calls in a preserved seasonal forest of the Austral Neotropics, with a description of a new species of Corethrella (Diptera: Corethrellidae). Zoological Science 33 (5): 527-536.

https://doi.org/10.2108/zs150173

Camp J.V. \& Irby W.S. 2017. Molecular confirmation of frogs (Anura) as hosts of Corethrellidae (Diptera) in the southeastern United States. Journal of Insect Science (Online) 17 (5).

https://doi.org/10.1093/jisesa/iex068

Guillaumet J.L. \& Kahn F. 1982. Structure et dynamisme de la forêt. Acta Amazonica 12: 61-77. https://doi.org/10.1590/1809-43921982123S061

Johnson R.N., Young D.G. \& Butler J.F. 1993. Trypanosome transmission by Corethrella wirthi (Diptera: Chaoboridae) to the green treefrog, Hyla cinerea (Anura: Hylidae). Journal of Medical Entomology 30 (5): 918-921. https://doi.org/10.1093/jmedent/30.5.918

Kvifte G.M. \& Bernal X.E. 2018. A new species of frog-biting midge from Papua New Guinea with a key to the described Corethrellidae of the Australopapuan region (Diptera, Corethrellidae, Corethrella). ZooKeys 795: 39-48. https://doi.org/10.3897/zookeys.795.28543

Lima A.P., Erdtmann L.K., Ferrão M., Costeira J.M., Oliveira A.S., Oliveira D.M.S. \& Silva K.M. 2012. SAPOTECA: biblioteca de sons e vídeos de anuros amazônicos.

Available from https://ppbio.inpa.gov.br/sapoteca/paginainicial [accessed 29 Oct. 2021].

McKeever S. 1977. Observations of Corethrella feeding on tree frogs. (Hyla). Mosquito News 37 (3): $522-523$.

McKeever S. \& Hartberg W.K. 1980. An effective method for trapping adult female Corethrella (Diptera: Chaoboridae). Mosquito News 40 (1): 111-112.

Meuche I., Keller A., Ahmad Sah H.H., Ahmad N. \& Grafe T.U. 2016. Silent listeners: can preferences of eavesdropping midges predict their hosts' parasitism risk? Behavioral Ecology 27 (4): 995-1003. https://doi.org/10.1093/beheco/arw002 
Pugedo H., Barata R.A., França-Silva J.C., Silva J.C. \& Dias E.S. 2005. HP: um modelo aprimorado de armadilha luminosa de sucção para a captura de pequenos insetos. Revista da Sociedade Brasileira de Medicina Tropical 38 (1): 70-72. https://doi.org/10.1590/S0037-86822005000100017

Ribeiro J.E. 1998. Flora da Reserva Ducke. Guia de identificação das Plantas vasculares de uma Floresta de Terra-firme na Amazônia Central. First Edition. INPA.

Rojas-Ahumada D.P., Landeiro V.L. \& Menin M. 2012. Role of environmental and spatial processes in structuring anuran communities across a tropical rain forest. Austral Ecology 37 (8): 865-873.

https://doi.org/10.1111/j.1442-9993.2011.02330.x

Toledo L.F., Ruggeri J., Campos L.L.F. de, Martins M., Neckel-Oliveira S. \& Breviglieri C.P.B. 2021. Midges not only sucks, but may carry lethal pathogens to wild amphibians. Biotropica 53 (3): 722-725. https://doi.org/10.1111/btp.12928

Toma T., Miyagi I., Higa Y., Okazawa T. \& Sasaki H. 2005. Culicid and Chaoborid flies (Diptera : Culicidae and Chaoboridae) attracted to a CDC miniature frog call trap at Iriomote Island, the Ryukyu Archipelago, Japan. Medical Entomology and Zoology 56 (2): 65-71.

https://doi.org/10.7601/mez.56.65_1

Wirth W.W. \& Marston N. 1968. A method for mounting small insects on microscope slides in Canada balsam. Annals of the Entomological Society of America 61 (3): 783-784.

https://doi.org/10.1093/aesa/61.3.783

Manuscript received: 10 March 2021

Manuscript accepted: 30 September 2021

Published on: 23 November 2021

Topic editor: Nesrine Akkari

Section editor: Torbjørn Ekrem

Desk editor: Solène Kowalski

Printed versions of all papers are also deposited in the libraries of the institutes that are members of the EJT consortium: Muséum national d'histoire naturelle, Paris, France; Meise Botanic Garden, Belgium; Royal Museum for Central Africa, Tervuren, Belgium; Royal Belgian Institute of Natural Sciences, Brussels, Belgium; Natural History Museum of Denmark, Copenhagen, Denmark; Naturalis Biodiversity Center, Leiden, the Netherlands; Museo Nacional de Ciencias Naturales-CSIC, Madrid, Spain; Real Jardín Botánico de Madrid CSIC, Spain; Zoological Research Museum Alexander Koenig, Bonn, Germany; National Museum, Prague, Czech Republic.

\section{Supplementary file}

Supp. file 1. List of song of frogs, found in 'sapoteca' frog library, with (https://ppbio.inpa.gov.br/ sapoteca/paginainicial). https://doi.org/10.5852/ejt.2021.778.1577.5473 